УДК 629.083

UDK 629.083

Молодан А.O.

Харківський наиіональний автомобільно-дорожній університет

\title{
ВИЗНАЧЕННЯ ПОТУЖНОСТІ І РОБОТИ ВИМУШЕНИХ КОЛИВАНЬ ПРИ ВІДКЛЮЧЕННІ ЦИЛІНДРІВ В ДВИГУНІ КОЛІСНОЇ МАШИНИ
}

\footnotetext{
В даній статті наведені результати по потужності вимушених коливань двигуна та енергетичну діаграму для вимушених коливань. Отримані залежності накладення вільних і вимушених коливань для різних умов спів падіння відносної частоти на величину потужності. Розглянуті перехідні процеси при вимушених коливаннях. Необхідність покращення рівномірності крутного моменту під час відключення циліндрів потребує впливу на показники потужності окремих циліндрів. Щоб знайти загальне рішення, потрібно додати вирази для вільних коливань, тобто загальне рішення однорідного рівняння.

В цій роботі також виявляється можливим виділити активну і реактивну складові. Активна робота зростає лінійно з часом, в той час як реактивна робота $\epsilon$ періодичною функцією часу. Поряд з зовнішньою збурюючою силою роботу здійснюють також і внутрішні сили коливальної системи. Робота сили інерції дорівнює кінетичної енергії маси, а робота поновлюючої сили дорівнює потенційної енергії напруженою пружини. При періодичних рухах обидві ці роботи також змінюються періодично i, маючи різні знаки, виключаються із загального балансу енергії системи, якщо їх величина розраховується для одного повного коливання.

Отримано відношення додаткових витрат енергії, зумовлених роботою стиснення робочих циліндрів у відключених циліндрах до зміни додаткових витрат енергії двигуна.

Поряд з вібрацією двигуна роботу здійснюють також і внутрішні сили коливальної системи. Робота сили інерції дорівнює кінетичної енергії маси, а робота оновлюючої сили дорівнює потенційної енергії напруженою подушками двигуна. При періодичних рухах обидві ці роботи також змінюються періодично i, маючи різні знаки, виключаються із загального балансу енергії системи, якщо їх величина розраховується для одного повного коливання. Таким чином, обидві роботи є реактивними. Робота, чинена силами демпфування за один повний період, не виключається із загального балансу.

Ключові слова: потужність, робота, вимушені коливання, відключення циліндрів, двигун, колісна машина, обурюючи сила.
}

\section{ВСТУП}

При призначенні режиму роботи двигуна з відключеним циліндром потрібно враховувати, що при виключенні циліндра і особливо при розбиранні руху порушуються динамічні властивості двигуна (збільшується ступінь нерівномірності обертання; при розбиранні деталей руху змінюється врівноваженість, посилюються крутильні коливання). В результаті змін динамічних властивостей при відключенні циліндрів може посилитися вібрація автотракторного двигуна і кузову колісної машини, що потребує подальшого зниження оборотів двигуна.

\section{АНАЛІЗ ОСТАННІХ ДОСЯГНЕНЬ І ПУБЛІКАЦІЙ}

Аналіз досліджень, проведених на двигунах показали [1], що при відключенні половини його циліндрів будь-яким 3 трьох способів (позначення: 1 - впускні і випускні клапани непрацюючих циліндрів постійно закриті, 2 - припинення подачі палива в непрацюючі циліндри, 3 - теж, але з усуненням насосних ходів у непрацюючих циліндрів, 4 - робота всіх циліндрів) вібрація збільшується. Зі збільшенням частоти обертання колінчатого валу різниця в умовах вібрації автотракторного двигуна при відключенні циліндрів може змінюватися. Найменший іiї рівень при варіанті (3), а максимальний при варіанті (1), пункт (2) залишається кращим, так як вібрація невелика, а спосіб відключення подачі палива найпростіший вимагає невеликі зміни конструкції дизеля, які реально здійсненні [2].

Примусова дезактивація циліндрів окрім безперечних переваг має ряд недоліків, які перешкоджають масовому застосуванню відключення циліндрів у двигунах автомобілів. Серед них слід відзначити різке зниження крутного моменту і збільшення його нерівномірності при відключенні частини циліндрів [3], особливо в момент переходу на меншу кількість навантажених циліндрів. Необхідність покращення рівномірності крутного моменту під час відключення циліндрів потребує впливу на показники потужності окремих циліндрів.

\section{МЕТА I ПОСТАНОВКА ЗАДАЧІ}

Метою даного дослідження є визначення потужності та роботи вимушених коливань, що виникає при відключенні циліндрів в двигуні колісної машини.

Для досягнення зазначеної мети необхідно вирішити наступні задачі:

- представити коефіцієнти підсилення по потужності вимушених коливань двигуна та енерге- 
тичну діаграму для вимушених коливань;

- отримати залежності накладення вільних і вимушених коливань для різних умов спів падіння відносної частоти на величину потужності;

- визначити додаткові витрати енергії, зумовлені роботою стиснення робочих циліндрів у відключених циліндрах до зміни додаткових витрат енергії двигуна.

\section{РЕЗУЛЬТАТИ ДОСЛІЖЕНЬ}

У автотракторного двигуна потужність коливань $L$ розраховується як скалярний добуток вектора сили $\vec{K}$ і вектора швидкості $\vec{x}[4]$

$$
L=\vec{K} \cdot \vec{x}
$$

Якщо за напрямом сила і швидкість збігаються, то можна взяти звичайне твір $K \cdot x$. В іншому випадку підставляють лише складову сили, спрямовану по швидкості.

В разі періодичної обурюючої сили будемо мати [4]

$$
K=K_{0} \cdot \cos \Omega t
$$

Якщо амплітуду вимушених коливань у загальному випадку позначити через $A$, той рух, що викликається періодично змінюється силою [4], описується формулою

$$
x=A \cdot \cos (\Omega t-\varphi) .
$$

Підставляючи ці вирази у формулу (1), після нескладних тригонометричних перетворень отримуємо потужність коливань [4]

$$
L=K \cdot x=1 / 2 K_{0} \cdot A \cdot \Omega[\sin \varphi-\sin (2 \Omega t-\varphi)]=L_{m}-L_{s}
$$

Таким чином, потужність можна представити у вигляді суми постійної складової $L_{m}$ (середня потужність) і періодичної складової $L_{s}$. Складова $L_{s}$ змінюється з частотою, удвічі більше частоти обурюючої сили. Користуючись термінологією $[4,5]$, потужність $L_{m}$ можна назвати активною, а потужність $L_{s}$ - реактивною.

Підставляючи відповідні значення $K_{0}$ и $A$, справедливих у загальному випадку співвідношень (4) легко знайти вирази для потужності для всіх приватних випадках. Так для випадку $A$ вважаємо, що на масу $m$ діє сила $K(t)=K_{0} \cos \Omega t=c \cdot x_{0} \cdot \cos \Omega t$, маємо

$$
\begin{gathered}
A=x_{0} \cdot V_{A}=\frac{x_{0}}{\sqrt{\left(1-\eta^{2}\right)^{2}+4 D^{2} \eta^{2}}}, \\
\sin \varphi=\frac{2 D \eta}{\sqrt{\left(1-\eta^{2}\right)^{2}+4 D^{2} \eta^{2}}} .
\end{gathered}
$$

Враховуючи, далі, що $\Omega=\omega_{0} \eta$, отримуємо

$$
\begin{gathered}
L_{m}=c \cdot x_{0}^{2} \cdot \omega_{0} \frac{D \eta^{2}}{\left(1-\eta^{2}\right)^{2}+4 D^{2} \eta^{2}}=c \cdot x_{0}^{2} \cdot \omega_{0} \cdot V_{m}, \\
L_{s}=c \cdot x_{0}^{2} \cdot \omega_{0} \frac{\eta}{2 \sqrt{\left(1-\eta^{2}\right)^{2}+4 D^{2} \eta^{2}}} \sin (2 \Omega t-\varphi)= \\
=c \cdot x_{0}^{2} \cdot \omega_{0} \cdot V_{s} \sin (2 \Omega t-\varphi)
\end{gathered}
$$


Множник $c \cdot x_{0}^{2} \cdot \omega_{0}$ має розмірність потужності, а $V_{m}$ и $V_{s}$ можна розглядати як безрозмірні коефіцієнти підсилення потужності. Ці вирази описують вплив коефіцієнта демпфування $D$ і відносної частоти $\eta$ на величину потужності. Абсолютно аналогічно тому, як це робилося при побудові амплітудних характеристик, можна побудувати «резонансні» криві для потужності. 3 (8) легко бачити, що $V_{m}$ так і $V_{s}$, дорівнює нулю при $\eta=0$ і при $\eta \rightarrow \infty$. Між тим обидва сімейства кривих незалежно від величини $D$ при $\eta=1$ мають максимум, рівний

$$
\left(V_{m}\right)_{\max }=\left(V_{s}\right)_{\max }=1 /(4 D) .
$$

Це означає, що при частоті збурення $\Omega=\omega_{0}$ середня потужність (активна потужність) дорівнює максимальному значенню змінної потужності (реактивної потужності). Таким чином, при введенні в коливальну систему певної корисної потужності в системі повинна розвиватися така реактивна потужність, максимальні значення якої має ту саму величину, що й активна потужність. Якщо обурення відбувається не з частотою $\Omega=\omega_{0}$, відношення активної потужності до реактивної зменшується. 3 (8) легко отримати

$$
\frac{L_{m}}{\left(L_{s}\right)_{\max }}=\frac{V_{m}}{V_{s}}=\frac{2 D \eta}{\sqrt{\left(1-\eta^{2}\right)^{2}+4 D^{2} \eta^{2}}} .
$$

Звідси безпосередньо видно, що якщо нам двигун з можливо низькою реактивною потужністю то краще перейти до резонансного випадку.

На рисунку 1 в якості прикладу показана функція $V_{m}$. Криві при $D>0,259$ монотонні, так що при цьому розвивається тим більша потужність, чим вище частота збурення.

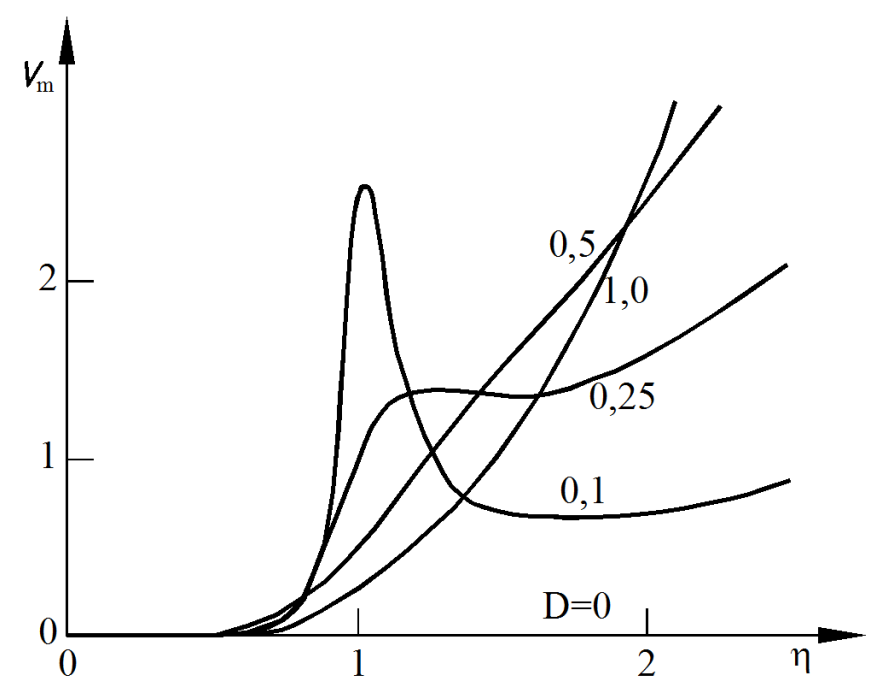

Рисунок 1 - Коефіцієнти підсилення по потужності вимушених коливань двигуна

Чинену роботу можна знайти інтегруванням потужності. Беручи до уваги рівність (2), отримують роботу зовнішньої сили збурення

$$
E_{e}=\int L d t=1 / 2 K_{0} \cdot A \cdot \Omega t \cdot \sin \varphi+1 / 4 K_{0} \cdot A \cdot \cos (2 \Omega t-\varphi),
$$

В цій роботі також виявляється можливим виділити активну і реактивну складові. Активна робота зростає лінійно $з$ часом, в той час як реактивна робота $є$ періодичною функцією часу. На практиці цікавляться передусім роботою $E^{*}$, чиненої за одне повне коливання 


$$
E_{e}^{*}=E_{e}(t=2 \pi / \Omega)-E_{e}(t=0)=\pi K_{0} A \sin \varphi .
$$

Поряд 3 зовнішньою обурюючою силою роботу здійснюють також і внутрішні сили коливальної системи. При цьому одержуємо наступні вирази для роботи

сила інерції $E_{\tau}=\int m x x d t=1 / 2 m x^{2}$,

сила демпфірування $E_{D}=\int d x x d t$,

оновлююча сила $E_{R}=\int c x x d t=1 / 2 c x^{2}$.

Робота сили інерції дорівнює кінетичної енергії маси, а робота поновлюючої сили дорівнює потенційної енергії напруженою пружини. При періодичних рухах обидві ці роботи також змінюються періодично i, маючи різні знаки, виключаються із загального балансу енергії системи, якщо їх величина розраховується для одного повного коливання. Таким чином, обидві роботи є реактивними. Робота, чинена силами демпфування за один повний період, не виключається із загального балансу.

При $x=-\Omega \cdot A \cdot \sin (\Omega t-\varphi)$ маємо

$$
E_{D}^{*}=d \Omega A^{2} \int_{0}^{2 \pi} \sin ^{2}(\Omega t-\varphi) d(\Omega t)=\pi d A^{2} \Omega
$$

Навпаки при $A>A_{s}$ споживана демпфіруванням енергія більше енергії, виробленої зовнішньою силою (рис. 2), і внаслідок цього відбувається зменшення амплітуди. При $A=A_{s}$ обидві роботи $є$ рівними між собою

$$
E_{e}^{*}=\pi K_{0} A_{s} \sin \varphi=E_{D}^{*}=\pi d A_{s}^{2} \Omega,
$$

звідки і виходить стаціонарна амплітуда

$$
A_{s}=\frac{K_{0} \sin \varphi}{d \Omega} .
$$

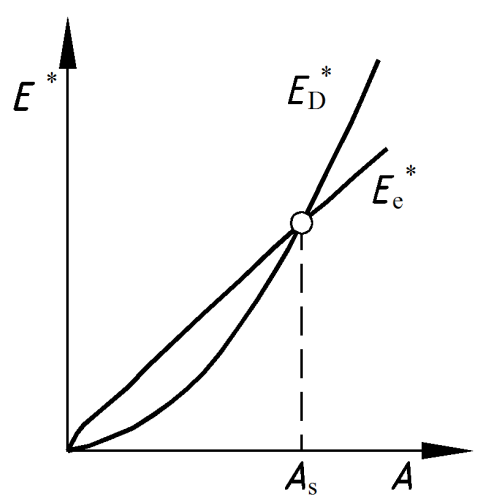

Рисунок 2 - Енергетична діаграма для вимушених коливань

Перехідні процеси при вимушених коливаннях. Щоб знайти загальне рішення, потрібно додати вирази для вільних коливань, тобто загальне рішення однорідного рівняння. Отже, рішення має вигляд

$$
x=x_{0} V \cos (\eta \tau-\varphi)+C e^{-D \tau} \cos \left(\sqrt{1-D^{2}} \tau-\varphi\right) .
$$

При належному виборі постійних $C$ і $\varphi$ це рішення буде задовольняти будь-яким заданим початковим умовам. В залежності від частоти збурення, власної частоти і виду початкових умов можливо надзвичайно велика кількість типів коливань. Дві криві $x(\tau)$ з початковими умовами $t=0$, $x=x^{\prime}=0$ побудовані на рисунках 3 а и $3 б$. 
Особливий інтерес представляє поведінку двигуна у випадку [6], коли власна частота і частота збурення близькі один до одного. Тут ми обмежимося лише розглядом недемпфованих коливань $D=0$; тоді вираз (17) прийме вид

$$
x=x_{0} \frac{1}{1-\eta^{2}} \cos \eta \tau+C \cos (\tau-\varphi) .
$$

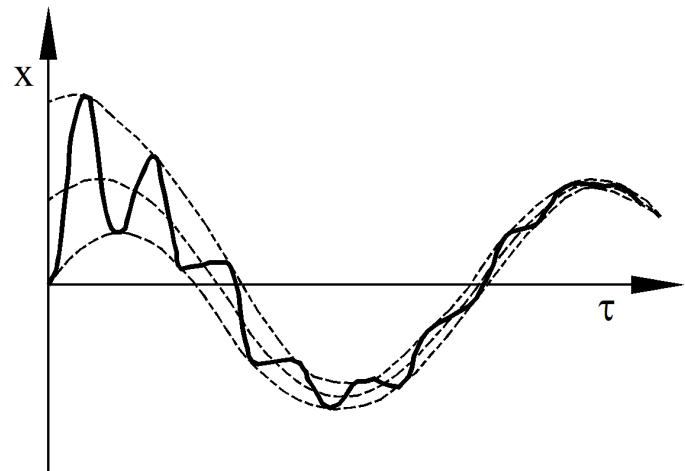

a

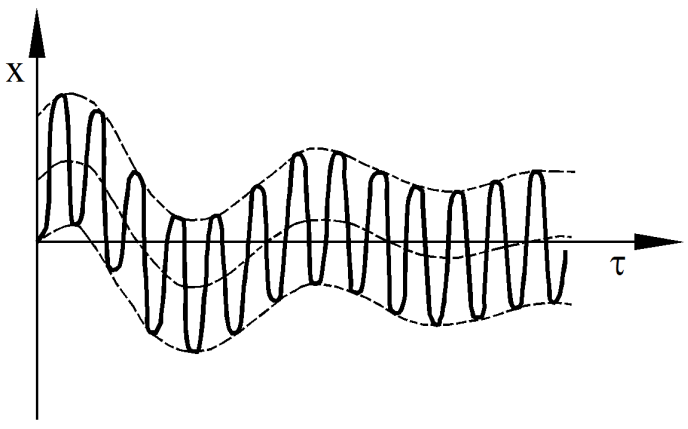

б

Рисунок 3 - Накладення вільних і вимушених коливань: a - у разі $\eta \triangleleft 1 ; \sigma-$ у разі $\eta \triangleright 1$.

Якщо постійні $C$ и $\varphi$ визначити з початкових умов $t=0, x=x^{\prime}=0$, то вийде

$$
C=-\frac{x_{0}}{1-\eta^{2}}, \varphi=0
$$

При цьому вираз переходить у наступне

$$
x=\frac{x_{0}}{1-\eta^{2}}(\cos \eta \tau-\cos \tau) .
$$

Тригонометричними перетвореннями це вираз приводиться до форми

$$
x=-\frac{2 x_{0}}{1-\eta^{2}} \sin \frac{\eta-1}{2} \sin \frac{\eta+1}{2} \tau .
$$

Це справедливе в загальному випадку вираз допускає особливо наочне тлумачення при $\eta \approx 1$, тобто у випадку, коли власна частота і частота обурення мало відрізняються один від одного. У цьому випадку виконується нерівність $(\eta-1) \triangleleft(\eta+1)$ i, отже, аргумент першої функції синуса буде змінюватися повільно порівняно зі змінами другий аргумент функції синуса. Таким чином, рух можна уявити собі як коливання з частотою $(\eta+1) / 2 \approx 1$, амплітуда якого $A(t)$ повільно змінюється за гармонійним законом

$$
A(t)=-\frac{2 x_{0}}{1-\eta^{2}} \sin \frac{\eta-1}{2} \tau
$$




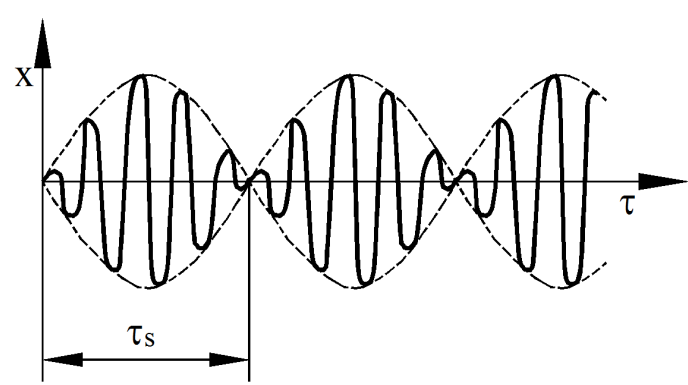

a

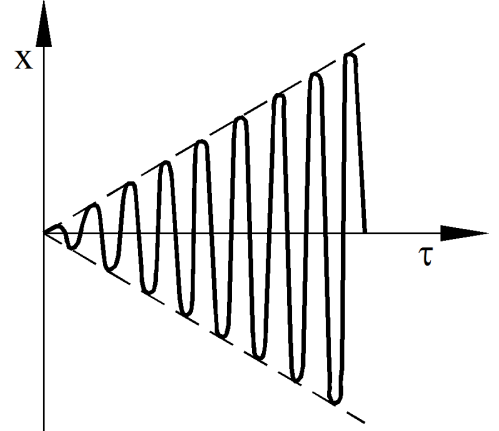

6

Рисунок 4 - Накладення вільних та вимушених коливань: а - у разі $\eta \approx 1$ при $D=0 ;$ б - у випадку резонансу $\eta=1$ при $D=0$.

Крива в плоскості $x$, для цих коливань зображена на рисунку 4а. Двигуни здійснюють коливання типу биттів, причому часовий інтервал між двома мінімумами обчислюється за формулою

$$
\tau_{s}=\frac{2 \pi}{\eta-1}
$$

Розгляд приватного рішення дає практично непридатний результат, так як у випадку $D=0$ коефіцієнт підсилення при $\eta=1$ звертається в нескінченність. Однак, беручи до уваги, що $\eta \approx 1$, рівняння можна записати наступним чином

$$
x=-\frac{2 x_{0}}{(1+\eta)(1-\eta)} \frac{\eta-1}{2} \tau \sin \frac{\eta+1}{2} \tau .
$$

Переходячи до межі, при $\eta \rightarrow 1$ будемо мати

$$
x=\left(x_{0} / 2\right) \tau \sin \tau .
$$

Це рівняння описує коливання з лінійно наростаючої з часом амплітудою, як показано на рисунку 4 б. Втім, легко переконатися, що рисунок 4 б виходить з рисунка 4 а при $\tau_{s} \rightarrow \infty$, тобто при зсуві першого мінімуму вправо до нескінченності. Справді, із рівняння (22) видно, що при $\eta \rightarrow 1$ період биттів $\tau_{s}$ необмежено зростає.

Співвідношення додаткових витрат енергії (викликаних нерівномірністю крутного моменту ДВ3) між варіантом з усіма працюючими циліндрами і варіантом відмови частини 3 них [7]

$$
\frac{\Delta W^{\prime \prime}}{\Delta W^{\prime}}=\frac{1}{1-\frac{\Delta i_{\text {ц }}}{i_{\text {u }}^{\prime}}}\left(1-\frac{0,08 \cdot \frac{\Delta i_{\text {щ }}}{i_{\text {u }}^{\prime}}}{0,08+\frac{14,44}{i_{\text {u }}^{\prime}}}\right) .
$$

де $\Delta W^{\prime}, \Delta W^{\prime \prime}$ - додаткові витрати енергії двигуна при всіх працюючих циліндрах і відключення частини з них;

$i_{\text {u }}^{\prime}$ - число циліндрів ДВ3;

$\Delta i_{\text {ц }}$ - число циліндрів, що відмовили.

Причому крутний момент дорівнює 


$$
\overline{M_{i}}=\frac{\overline{N_{i}}}{\omega_{e}}=\frac{\overline{N_{i}} \cdot r_{\partial}}{V_{\text {авт }} \cdot u_{\mathrm{K}} \cdot u_{0}}=\frac{N_{e} \cdot r_{\partial}}{\eta_{\mathrm{M}} \cdot V_{\text {авт }} \cdot u_{\mathrm{K}} \cdot u_{0}},
$$

При підстановці отримаємо відношення додаткових витрат енергії, зумовлених роботою стиснення робочих циліндрів у відключених циліндрах до зміни додаткових витрат енергії двигуна

$$
\frac{\delta \Delta W_{2}}{\delta \Delta W_{1}}=\frac{\Delta i_{\text {ц }} \cdot p_{a} \cdot V_{a} \cdot \frac{\left(\varepsilon^{n-1}-1\right)}{n-1} \cdot V_{\text {авт }} \cdot u_{\text {к }} \cdot u_{0}}{2 \cdot N_{e} \cdot r_{\partial} \cdot \eta_{\text {тр }} \cdot\left(0,08+\frac{\frac{14,44}{i_{\text {u }}^{\prime}}}{1-\frac{\Delta i_{\text {ч }}}{i_{\text {u }}^{\prime}}}\right)}>1,
$$

Поряд 3 вібрацією двигуна роботу здійснюють також і внутрішні сили коливальної системи. Робота сили інерції дорівнює кінетичної енергії маси, а робота оновлюючої сили дорівнює потенційної енергії напруженою подушками двигуна. При періодичних рухах обидві ці роботи також змінюються періодично i, маючи різні знаки, виключаються із загального балансу енергії системи, якщо їх величина розраховується для одного повного коливання. Таким чином, обидві роботи є реактивними. Робота, чинена силами демпфування за один повний період, не виключається із загального балансу.

\section{ВИСНОВКИ}

1. Представлені коефіцієнти підсилення по потужності вимушених коливань двигуна та енергетичну діаграму для вимушених коливань. В якості прикладу показана функція $V_{m}$. Криві при $D>0,259$ монотонні, так що при цьому розвивається тим більша потужність, чим вище частота збурення.

2. Отримані залежності накладення вільних і вимушених коливань для різних умов спів падіння відносної частоти на величину потужності. Розглянуті перехідні процеси при вимушених коливаннях. Щоб знайти загальне рішення, потрібно додати вирази для вільних коливань, тобто загальне рішення однорідного рівняння.

3. Отримано відношення додаткових витрат енергії, зумовлених роботою стиснення робочих циліндрів у відключених циліндрах до зміни додаткових витрат енергії двигуна.

\section{ПЕРЕЛІК ДЖЕРЕЛ ПОСИЛАННЯ}

1. Валеев Д.Х. Возможности улучшения экономических и экологических свойств дизелей КамАЗ740 отключением цилиндров и циклов на режимах холостых ходов и малых нагрузок / Д.Х. Валеев, В.А. Гергенредер, И.Ю. Олесов, Н.Н. Патрахальцев // Двигателестроение. - 1991. - № 8-9. - С. 62-69.

2. Хімченко А.В. Зниження нерівномірності крутного моменту двигуна з відключенням циліндрів на режимах часткового навантаження / А.В. Хімченко, Д.Г. Мішин, А.В. Бузов // Двигатели внутреннего сгорания/-2013. - № 1. - С. 46-51.

3. Peters, G. Cylinder deactivation on 4 cylinder engines: A torsional vibration analysis [text]/ Gilbert Peters // Eindhoven University of Technology (TU/e). - 2007. - 75 c.

4. Магнус К. Колебания: Введение в исследования колебательных систем / К. Магнус: [Пер. с нем.]. - М.: Мир, 1982. - 304 с.

5. Тимошенко С.П. Колебания в инженерном деле / С.П. Тимошенко, Д.Х. Янг, У. Уивер: [Пер. с англ. Л.Г. Корнейчука; Под ред. Э.И. Григолюка] // М.: Машиностроение, 1985. - 472 с.

6. Молодан А.А. Теоретические расчеты относительного дополнительного расхода топлива при отключении цилиндров / А.А. Молодан, А.С. Полянский // Науковий журнал «Інженерія природокористування». - Харківський національний технічний університет сільського господарства імені Петра Василенка. - №2 (10), 2018. - С. 14-18.

7. Молодан А.О. Метод визначення додаткових витрат енергії викликаних нерівномірністю крутного моменту двигуна при відключенні циліндрів / А.О. Молодан // Вісник машинобудування та транспорту. - 2018. - № 2(8). - С. 65-73. 


\section{REFERENCES}

1. Valeev D. H., Gergenreder V. A., Olesov I. Ju., \& Patrahal'cev N. N. (1991). Vozmozhnosti uluchshenija jekonomicheskih i jekologicheskih svojstv dizelej KamAZ-740 otkljucheniem cilindrov i ciklov na rezhimah holostyh hodov i malyh nagruzok. Dvigatelestroenie. № 8-9, 62-69.

2. Himchenko A. V., Mishyn D. G., \& Buzov A. V. (2013). Znyzhennja nerivnomirnosti krutnogo momentu dvyguna z vidkljuchennjam cylindriv na rezhymah chastkovogo navantazhennja. Dvygately vnutrennego sgoranyja. № 1, 46-51.

3. Gilbert Peters (2007). Cylinder deactivation on 4 cylinder engines: A torsional vibration analysis [text]. Eindhoven University of Technology (TU/e), 75 p.

4. Magnus K. (1982). Kolebanija: Vvedenie v issledovanija kolebatel'nyh sistem: [Tr. with Deutsch.]. M.: Mir. 304 p.

5. Timoshenko S. P., Jang D. H., \& Uiver U. (1985). Kolebanija v inzhenernom dele: [Tr. with English. Kornejchuka L.G.; pod red. Grigoljuka Je. I.]. M.: Mashinostroenie. 472 p.

6. Molodan A. A., \& Poljanskij A. S. (2018). Teoreticheskie raschety otnositel'nogo dopolnitel'nogo rashoda topliva pri otkljuchenii cilindrov. Naukovyj zhurnal «Inzhenerija pryrodokorystuvannja». Harkivs'kyj nacional'nyj tehnichnyj universytet sil's'kogo gospodarstva imeni Petra Vasylenka. №2 (10), 14-18.

7. Molodan A. O. (2018). Metod vyznachennja dodatkovyh vytrat energii' vyklykanyh nerivnomirnistju krutnogo momentu dvyguna pry vidkljuchenni cylindriv. Visnyk mashynobuduvannja ta transportu. № 2(8), PP. 65-73.

\section{A. Molodan. Determination of power and work of forced vibrations when the cylinders are discon- nected in the engine of the wheeled vehicle}

This article presents the results of the power of the forced oscillations of the engine and the energy diagram for the forced oscillations. Dependences of the imposition of free and forced oscillations for different conditions of coincidence of relative frequency on the magnitude of the power were obtained. The transient processes under forced oscillations are considered. The need to improve the torque uniformity during cylinder shutdown requires an impact on the performance of the individual cylinders. To find a common solution, you need to add expressions for free oscillations, that is, a general solution of a homogeneous equation.

In this work it is also possible to distinguish active and reactive components. Active work increases linearly over time, while jet work is a periodic function of time. Along with the external disturbing force, the internal forces of the oscillatory system also work. The work of the moment of inertia is equal to the kinetic energy of the mass, and the work of the restoring force is equal to the potential energy of the stressed spring. In periodic motions, both these jobs also change periodically and, having different signs, are excluded from the total energy balance of the system, if their value is calculated for one complete oscillation.

The ratio of additional energy consumption caused by the compression of the working cylinders in the disconnected cylinders to the change of the additional energy consumption of the engine is obtained.

Along with the vibration of the engine, the internal forces of the oscillatory system also perform work. The work of the inertia force is equal to the kinetic energy of the mass, and the work of the renewing force is equal to the potential energy of the stressed motor cushions. In periodic motions, both these jobs also change periodically and, having different signs, are excluded from the total energy balance of the system, if their value is calculated for one complete oscillation. Thus, both works are reactive. Work performed by damping forces for one complete period is not excluded from the overall balance.

Keywords: power, work, forced vibrations, cylinder shutdown, engine, wheeled vehicle, disturbing force.

МОЛОДАН Андрій Олександрович, кандидат технічних наук, доцент кафедри технології машинобудування і ремонту машин, Харківський національний автомобільно-дорожній університет е-таil: tmirm@ukr.net. https://orcid.org/0000-0002-0017-740X

Andrii MOLODAN, $\mathrm{PhD}$ in Engeneering, associate professor of Technology of Mechanical Engineering and Machine Repair department, Kharkiv National Automobile and Highway University e-mail: tmirm@ukr.net. https://orcid.org/0000-0002-0017-740X 